\title{
Estilos de desarrollo sustentable en el norte de Misiones
}

\author{
Raimundo Elías Gómez \& Brian German Ferrero
}

\begin{abstract}
resumen Este trabajo realiza un acercamiento a la esfera de la conservación y el desarrollo sustentable en el norte de Misiones. El eje central son los modos en que agencias ambientalistas encaran proyecciones e intervenciones conservacionistas en zonas de amortiguamiento de Áreas Naturales Protegidas. Al principio se esboza una caracterización de los departamentos de Iguazú y General Manuel Belgrano, así como de los inicios de la conformación de una gobernanza medioambiental. Luego se describen los principales proyectos de conservación y desarrollo sustentable estimulados por JICA (Japan International Cooperation Agency), y por AECID (Agencia Española de Cooperación Internacional para el Desarrollo). De manera concreta, las características principales del "Proyecto Cabureî" (JICA) así como de los proyectos producidos por Araucaria XXI (AECID). Hacia el final, se exponen consideraciones sobre problemáticas recurrentes que reúnen a poblaciones locales y agencias ambientalistas.
\end{abstract}

palabras claves Gobernabilidad. Desarrollo sustentable. Cosmografías. Ambientalismo.

\section{Introducción}

El trabajo sobre buffer zone ${ }^{1}$ de Áreas $\mathrm{Na}$ turales Protegidas ha comenzado a tomar relevancia a nivel global, a partir de la inclusión de las dimensiones socioculturales de poblaciones locales aledańas. Durante los últimos años el acercamiento entre la conservación del medio ambiente y el desarrollo, ha implicado como señala De Barros (1996, p. 125) el abandono de los conservacionistas de una "[...] posición periférica, y muchas veces negativa, hacia otras más positivas, en el centro de la arena internacional de las llamadas politicas de desarrollo". En la provincia de Misiones, en el noreste de Argentina, desde fines de la década de 1990 diversas agencias de conservación y desarrollo han comenzado a implementar proyectos que asocian objetivos de conservación del ambiente con las problemáticas de poblaciones contiguas a las Áreas Naturales Protegidas. Dentro de este marco general emerge un conjunto de proyectos e intervenciones, inherentes a la conservación y al desarrollo sustentable en el norte de Misiones. De manera que el gobierno de las áreas rurales de la región no está sólo a cargo de los diferentes organismos políticos del Estado, el nacional, provincial y el municipal. En particular en torno a las Áreas Naturales Protegidas, el gobierno es compartido entre distintas agencias gubernamentales, agencias internacionales de desarrollo y organizaciones no gubernamentales. Si bien el poder del Estado no desaparece, es negociado con organismos que en muchas situaciones son quienes establecen las líneas de acción preponderantes.

\section{La gobernabilidad del territorio}

La modernidad capitalista requirió del desarrollo de formas de gobierno sobre recursos y poblaciones basado en el conocimiento de expertos planificadores, estadistas, economis- 
tas y demógrafos, que Foucault (1991) ha denominado "gobernabilidad". Desde esta perspectiva, la gobernabilidad se presenta como un fenómeno moderno fundamental, por medio del cual vastos ámbitos de la vida cotidiana son apropiados, procesados y transformados de manera creciente por conocimientos experto y los aparatos administrativos del Estado. Así la gobernabilidad se construye sobre aparatos de planificación que establecen cómo debe ser la vida social, política y económica de las poblaciones. A su vez, tales aparatos regulan, simplifican, disciplinan, administran y planifican a las poblaciones, territorios y naturaleza, es decir, hecha objeto del conocimiento experto. El proceso de gobernabilidad se extiende al orden de los espacios naturales a partir del manejo planificado por parte del Estado y sobre conocimientos científicos de los bosques y la agricultura, la gestión del desarrollo sostenible y el manejo de los territorios y poblaciones. En las zonas buffer, en torno a las Áreas Naturales Protegidas de la provincia de Misiones, el gobierno de poblaciones, territorios y naturaleza no sólo el Estado interviene, en sus niveles municipal, provincia y nacional, sino también organizaciones no gubernamentales ambientalistas y de desarrollo, y agencias internacionales pertenecientes a los Estados español y japonés. Lemos y Agrawal (2006, p. 298) han denominado como "gobernabilidad ambiental" a este tipo de procesos donde un "conjunto de las regulaciones, procesos, mecanismos y organizaciones a través de los cuales los actores políticos influyen en las acciones ambientales y sus resultados”. En el caso aquí estudiado, este proceso de gobernabilidad implica por una parte luchas por la homogeneización de poblaciones locales, mientras por otro lado lleva a renegociaciones entre pobladores locales de acuerdo a sus condiciones sociales e intereses diferenciados.
En el presente artículo proponemos analizar las principales características que tiene la gobernabilidad que establecen el conjunto de agencias de conservación y desarrollo que actúan en la zona norte de la provincia de Misiones. En particular en las zonas buffer de las Áreas Naturales Protegidas, ya que esta es una región con predominio de Áreas Protegidas, lo que ha llevado al interés de diversas agencias por desplegar programas de conservación y desarrollo. En primer lugar, describiremos las principales programas que están actuando en la región, focalizaremos en los dos programas más importantes por presupuesto, territorio que abarcan y cantidad de años que llevan implementándose. Luego, analizaremos cómo el gobierno del territorio que estos programas desarrollan, lleva a definir o crear de manera particulares territorios y poblaciones. Un elemento central de estos programas radica en la necesidad de involucrar a las "poblaciones locales" en el gobierno de los territorios, en el análisis de esto desarrollamos las respuestas de las poblaciones locales frente tales propuestas.

\section{0 años de proyectos de conservación en la selva misionera}

La Selva Paranaense ha estado en la mira de la comunidad conservacionista internacional desde hace más de dos décadas. En 1994 tiene lugar uno de los hitos iniciales en el interés internacional por esta región, cuando se realizaron una serie de talleres en los que estuvieron involucradas instituciones con incumbencia en Áreas Naturales Protegidas de tres países donde se presenta la Selva Paranaense: Brasil, Argentina y Paraguay. Por parte de Argentina participaron APN (Administración de Parques Nacionales), la presidencia del Parque Nacional Iguazú, el Ministerio de Ecología y Recursos Naturales Renovables (MERNRyT) 
dependiente del gobierno provincial, los gobiernos municipales de Iguazú y de Andresito, y la ONG nacional Fundación Vida Silvestre Argentina. Estas reuniones se realizaron con el apoyo de UICN (Unión Internacional para la Conservación de la Naturaleza) y WWF (World Wildlife Fund), que impulsaban el diseño e implementación de acciones de conservación transfronterizas. En uno de estos talleres, realizado en Hernandarias (Paraguay), en 1996, se concluyó que de manera urgente se debía construir un "Corredor Biológico Trinacional”. Este corredor cubriría un área extensa que se extendería incluyendo la Reserva $\mathrm{Na}$ tural del Bosque Mbaracayú y el Monumento Científico Moisés Bertoni en Paraguay, los Parques Nacionales do Iguaçú en Brasil e de Iguazú en Argentina, hasta el Parque Provincial Moconá en Argentina y el Parque Estadual do Turvo en Brasil. Con tal extensión se abarcaba más de la mitad de la superficie de la provincia de Misiones.

Las relaciones transnacionales entre las agencias estatales y descentralizadas operantes en los tres países continuaron, y uno de los resultados de las interdependencias generadas involucró a Misiones. El proceso de constituir un Área Natural Transfronteriza, no consiguió concretarse, pero como resultado de estas discusiones, a fines de 1999 el poder legislativo de la provincia de Misiones, sancionó la creación de un "Área Integral de Conservación y Desarrollo Sustentable" denominado Corredor Verde Misionero. Un Área Protegida que se extiende por el centro y norte de Misiones con una superficie de un millón de hectáreas que incluye pequeños centros urbanos, grandes explotaciones forestales, medianas y pequeñas unidades productivas rurales, y Reservas Naturales estrictas. En la sanción de la ley estuvieron presentes directivos de WWF internacional, mostrando el interés de la agencia conserva- cionista internacional por la selva misionera. En la creación del Corredor Verde Misionero se señala la necesidad de esfuerzos "serios $y$ efectivos" (Giraudo et al, 2003) de educación ambiental para que las poblaciones aledañas puedan tener beneficios directos de las áreas protegidas, aunque siempre a condición de que, como señalaron especialistas de JICA no se afecte el derecho de las generaciones futuras y de la comunidad más amplia (Japan Wildlife Research Centre, 2005).

Conforme se gestaban las primeras interdependencias transnacionales que ponían en el orden del día, se enfatizaba la necesidad de alianza entre desarrollo y conservación, así como de trabajar sobre "zonas de amortiguamiento" de Áreas Naturales Protegidas. Durante la década de 1990 se llevaron a cabo numerosos talleres, charlas, cursos, seminarios, sobre educación ambiental tendientes a generar compromisos más fuertes con la naturaleza y a capacitar técnicos y personal de agencias locales (Administración de Parques Nacionales, Instituto Nacional de Tecnología Agraria, MERNRyT, Municipalidad de Iguazú y Andresito, etc.). En este contexto, el CIES (Centro de Investigaciones Ecológicas Subtropicales), dependiente del Parque Nacional Iguazú inicia en 1996 el "Proyecto Tigre" (Proyecto Yaguareté a partir de 2004) que establece la urgencia de establecer estrategias de conservación del yaguareté en la zona del PNI y alrededores. A tono con las recomendaciones y compromisos del momento, las estrategias elaboradas por técnicos e investigadores retomaban charlas y talleres con productores rurales, debido a que el doble objetivo del proyecto buscaba (1) reducir una de las principales causas de muerte del felino y (2) disminuir las pérdidas económicas provocadas por el felino a los productores. Esta es una de las primeras acciones tendientes a abarcar las preocupaciones de las poblaciones aledañas a áreas naturales protegidas. 
Acerca de estos hechos, Ferrero (2007) señala la emergencia en Misiones de una cosmografía "ambientalista-colona” que persigue la articulación e interacción fluida entre técnicos y empleados de agencias ambientalistas, colonos y aborígenes. El concepto de "cosmografía” es retomado de Little por Ferrero (2007, p.35) para referir a "[...] las identidades colectivas e históricamente contingentes, ideologías y sistemas de conocimiento sobre el entorno desarrollados por un grupo social para establecer y mantener territorios humanos". Las poblaciones de los lugares donde tales procesos tienen lugar, pasan a ocupar nuevas posiciones frente al estado y las agencias de desarrollo y conservación, de modo que muchas poblaciones locales comienzan a ser integradas, no sin conflictos, a los procesos de creación de territorios ambientalistas (Ferrero, 2007; 2005). De la cosmografía ambientalista-colona los tipos de cooperación internacional tienen gran peso en la organización del desarrollo sustentable.

A partir de la década de 2000, los dos principales proyectos de conservación y desarrollo que se implementan corresponden a alianzas entre agencias gubernamentales: la Administración de Parques Nacionales (APN), el Ministerio provincial de Ecologia (MERNR), la ONG Fundación Vida Silvestre Argentina y la cooperación japonesa y española. Por un lado, encontramos a Cooperación española (AECID) coordinando las acciones del Proyecto Araucaria XXI, formando parte de alianzas de trabajo con APN, MERNR, junto a cooperativas y ONGs conservacionistas locales, desarrollando en conjunto planes de manejo de Áreas Naturales Protegidas, generando becas para investigación al interior de áreas naturales, y en otros casos apoyando líneas de trabajo de organismos estatales similares a la suya. Esto es, con los objetivos principales de mejorar la cali- dad de vida y la participación de poblaciones cercanas o involucradas de alguna manera con áreas naturales protegidas, y a propósito de la construcción de desarrollo sustentable. De otra parte, Cooperación japonesa (JICA) una de las principales líneas de cooperación internacional de la república Argentina, ofreciendo investigaciones y diagnósticos especializados, coordinando equipos de investigación, elaborando proyectos de ecoturismo, o brindando talleres, cursos y becas de intercambio con Japón a propósito del mejoramiento de la eficacia de sistemas de manejo y gestión de áreas naturales protegidas.

\section{Cooperación japonesa en el norte de Misiones. Proyecto Cabure í}

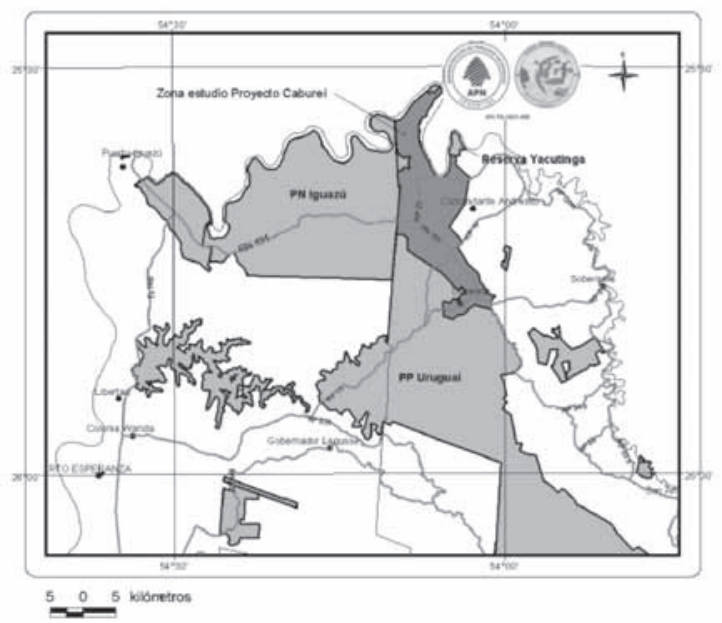

Mapa 1. Ubicación del área del Proyecto Cabure í. Mapa cedido por OPDR (Hugo Chávez). En color lila el área del Proyecto Cabure íy en color verde las áreas naturales protegidas.

La Cooperación Técnica entre Países en Desarrollo (CTPD), de la cual Argentina forma parte, comenzó a tomar impulso a partir de la Conferencia llevada a efecto por la Organización de las Naciones Unidas en la que se adoptó el Plan de Acción de Buenos Aires (1978). Las relaciones entre Argentina y Japón no son nue- 
vas, el convenio de cooperación entre ambos países de 1979 fue ratificado en 1981, y hasta la actualidad la implicancia de JICA en Argentina abarca áreas del desarrollo social, preservación del medio ambiente, desarrollo de la economía y apoyo a la cooperación horizontal. En este marco, en el año 2000, APN solicita asistencia técnica a JICA para diseñar la zona de amortiguamiento del Parque Nacional Iguazú. JICA por su parte contrata especialistas japoneses del Japan Wildlife Center que se encargan de esta asistencia. El Sector Este, que limita con la localidad de Comandante Andresito fue el sector prioritario, acerca del cual se elaboró un diagnóstico (Proyecto Cabure í, 2005). A partir de esas primeras tratativas y del envió de técnicos japoneses por JICA para evaluar y diseñar el plan del diagnóstico, fueron progresando las tratativas, hasta que finalmente en el año 2003 se firma el Acta de Deliberación (Record of Discussions) entre la APN, el Ministerio provincial de Ecología, la Municipalidad de Comandante Andresito y JICA. El nombre largo del resultado de esta acta de deliberación, iniciado en el año 2004, fue el de "Proyecto de Conservación del Ambiente Natural de la Región de Iguazú de la República Argentina”, años más tarde resumido como "Proyecto $\mathrm{Ca}$ bure î" (en adelante PC). Los objetivos del PC alentaban,

el mejoramiento del sistema de manejo del Parque Nacional Iguazú y de las áreas naturales protegidas provinciales, en especial del Corredor Verde, y el objetivo principal era el fortalecimiento del sistema de manejo de conservación del ambiente natural (Proyecto $\mathrm{Ca}$ bure í, 2005).

De manera específica, se trata de elevar la capacidad de manejo del ambiente natural del personal de la Administración de Parques Nacionales, del Gobierno provincial y de la
Municipalidad de Comandante Andresito, en el ámbito de la región del proyecto. Las actividades realizadas a propósito de este proyecto, fueron capacitaciones en educación ambiental y ecoturismo, diagnósticos sobre uso de la tierra en Cabure í, seminarios y disertaciones sobre usos y circulación de información, recepción de turistas japoneses y monitoreo de programas de educación ambiental y ecoturismo. El apoyo de JICA implicó tanto asistencia técnica como tecnológica, así como donaciones, y aportes financieros a proyectos conjuntos elaborados en la zona desde ese momento. El PC se inició en marzo de 2004, la cooperación de Japón se extendió hasta marzo de 2007, y luego volvió a renovarse en el 2008 hasta mediados del 2010. Actualmente la cooperación de JICA involucra al proyecto "Perspectiva de conservación de la biodiversidad de la Selva Atlántica interior en Misiones" (2008-2011), el organismo de contraparte es el MERNRyT, nuevamente Se trata de un proyecto que tiene como objetivo la formación de recursos humanos capacitados en la gestión de áreas protegidas y en la preservación de la biodiversidad en la Selva Atlántica de la Pcia. de Misiones (Ministerio de Producción Secretaría de Turismo y Administración de Parques, 2009). La acción de JICA se ejerce frecuentemente sobre "recursos humanos", tanto de organismos estatales, como de agencias ambientalistas descentralizadas. Mientras que las capacitaciones sobre técnicas y uso de tecnologías van integrados a modos más eficientes de gestión, aplicación y evaluación de proyectos sustentables.

\section{Cooperación española en el norte de Misiones}

En el año 2006, a la configuración del desarrollo en el norte de Misiones se suma el proyecto Araucaria XXI con el apoyo de la AE- 


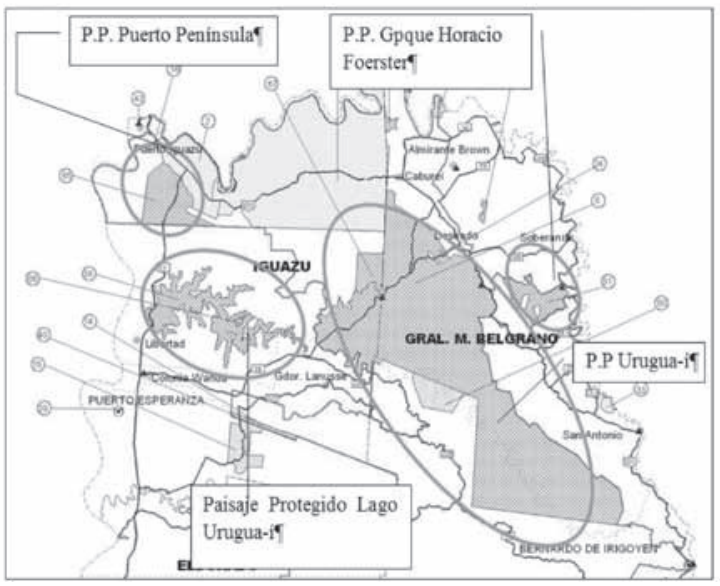

Mapa 2. Localización de principales áreas protegidas y poblaciones aledañas en el núcleo norte. Cedido por Área de planificación, Araucaria XXI (Nuria Manso).

CID (se trata de un acuerdo entre la Agencia Española de Cooperación Internacional para el Desarrollo, APN y MERNRyT). La cooperación española para Argentina, habilita ampliamente las posibilidades de la cooperación descentralizada, la cual permite vincular directamente a ONGs y organizaciones locales con financiamiento y coordinación de agencias transnacionales. Esta es una de las primeras diferencias con el accionar de la cooperación japonesa, estrechamente dependiente de acuerdos firmados entre representantes de los estados de Argentina y Japón.

El apoyo de JICA y la emergencia de Araucaria XXI, impulsaron el nacimiento de la OPDR (Oficina de proyectos de Desarrollo Regional) la cual se constituyó el 27 julio de 2005 como una dependencia de APN, con los objetivos de Coordinar actividades con las comunidades vecinas y otros organismos nacionales, provinciales, municipales y extranjeros al PN Iguazú, articulando con las demás instancias del mismo (OPDR, 2007). Esta oficina está ubicada al borde del Parque Nacional Iguazú y del Paraje Cabure í en Andresito, y funciona como eje de las actividades relacionadas con el desarrollo sustentable desarrolladas en la zona tanto por el Parque Nacional Iguazú, JICA, Araucaria XXI, el municipio de Andresito y organizaciones locales.

El "Plan de Manejo del Núcleo Norte de la Provincia de Misiones" elaborado en el 2007 con la participación de Araucaria XXI casi un año después de que ésta empieza a operar, incorporó enfáticamente la preocupación por articular las dimensiones naturales y culturales en la planificación del manejo de áreas protegidas (CURÍ, 2009). Esta preocupación llevó a incorporar temporalmente a investigadores y académicos provenientes de diferentes centros de investigación y enseñanza universitaria, tanto nacionales como internacionales. De otra parte, los organismos y agencias estatales y descentralizadas comprometidas en estos procesos son numerosos y procedentes de áreas diversas.

Durante el 2009 el equipo de Araucaria XXI tuvo como tareas prioritarias en materia de planificación la construcción de los Planes Estratégicos y de Manejo de las mayores Áreas Protegidas Provinciales del Núcleo Norte. Diferentes equipos de trabajo de Araucaria se dedicaron a trabajar las problemáticas de poblaciones aledańas al Parque Nacional Iguazú. De esta manera se generaron estrategias y modos de organización para articular por ejemplo, las actividades productivas de los aborígenes y su modo de vida, con los requerimientos del turismo. Los resultados fueron la construcción de stands para la exposición de artesanías y otros productos aborígenes, el armado de sendas y recorridos al interior del monte, y la capacitación para guiar y tratar a turistas extranjeros en lo que respecta a creencias y modos de vida de la población guaraní. Un papel muy importante desempeñado por Araucaria XXI respecto a las poblaciones aledañas a áreas naturales protegidas, ha estado relacionado con problemas jurídicos y políticos por ejemplo, con la tenencia legal de tierras, la usurpación de terrenos por parte de empresas, y 
la explotación ilegal de montes pertenecientes a aldeas aborígenes. Otras líneas de acción se han dedicado a la organización del cuidado de vertientes, de montes al interior de las chacras, y peligros vinculados a los agrotóxicos. Se crearon de esta manera equipos comunitarios de trabajo, cooperativas para tratar en conjunto problemáticas locales (Cooperativa Cabure í), y construir alternativas productivas en vistas a la sustentabilidad de los ecosistemas locales.

En la actualidad en el Núcleo Norte, Araucaria XXI implementa el proyecto de desarrollo sostenible para los pobladores locales asentados en las áreas de amortiguación del Parque Nacional Iguazú y de otras áreas protegidas provinciales, incluidas en el ámbito de incumbencia del Proyecto Araucaria XXI (Curí, 2010) Este proyecto es financiado por la Fundación Biodiversidad a través de la Asociación Territorios Vivos de España. El objetivo general del Proyecto en cuestión es favorecer el desarrollo sostenible de aldeas aborígenes y de los pequeños productores rurales del núcleo norte de la Provincia de Misiones. Fomentando de modo principal la creación y fortalecimiento de prácticas sustentables para mantener la biodiversidad del sistema en el área de amortiguación de los espacios protegidos (Curí, 2009, p. 2).

\section{La construcción de un nuevo territorio}

La ambientalización del territorio tiene lugar junto a cambios en la forma en que son conceptualizados los pobladores locales, ya sean las poblaciones de colonos, pequeños y medianos productores rurales de origen criollo o descendientes de inmigrantes europeos, o las poblaciones indígenas mbyá-guaraní. Durante la mayor parte del siglo XX, los colonos se presentaron como los heroicos constructores de la civilización en el interior de la provincia: ellos fueron quienes lucharon contra ese infier- no verde que es la selva, abrieron la muralla de selva para permitir que la producción agrícola enriqueciese a la nueva Misiones. Pero hacia finales de la década de 1990, cuando la frontera agraria estaba terminando de ocupar las tierras fiscales con selva y cuando se fortaleció la industria forestal, la imagen de los colonos se transforma, éstos comenzaron a ser presentados como los destructores de la selva, responsables por las pérdidas de la naturaleza. Por entonces, se multiplicaron en los diarios locales las noticias sobre incendios forestales que se originan en los rozados con fuego hechos por los colonos, a su vez que se hace subraya la poca colaboración que prestan para apagar los incendios. Esta imagen de los colonos sirvió para legitimar las políticas de creación de Áreas Naturales Protegidas como espacios de selva a salvo de los colonos, a su vez se asiste a enfrentamientos entre pobladores rurales y guardaparques.

En el caso de las comunidades mbya-guaraní, con el incentivo que se da durante todo el siglo XX al poblamiento de la provincia para el desarrollo agrícola, impulsado desde el Estado, las comunidades aborígenes que poblaban el territorio fueron invisibilidades, ya que no se correspondían con el ideal de sujeto nacional apto para el desarrollo. La visión que se tenía sobre estas comunidades respondía a una lógica de valores improductiva, lo que permitía su explotación como mano de obra. Con el predominio de las producciones agrícola y forestal, las poblaciones indígenas viven en general en latifundios de propiedad privada, y en tierras otorgadas por el Estado provincial, en condiciones de extrema pobreza, ocupándose, en general, como trabajadores jornaleros, en la producción y venta de artesanías, y la producción de subsistencia.

Pero a partir de la presencia en la región de agencias que buscan combinar la conservación con el desarrollo colonos e indios comienzan a ser presentado como potenciales aliados 
para la conservación. Los colonos pasan a ser considerados como poseedores de capacidades para una producción artesanal, a pequeña escala, que se opone al tipo de producción que llevan a cabo las grandes empresas forestales, que transforman grandes extensiones de selva en monocultivos de coníferas. Mientras a las comunidades indígenas se las valora por sus conocimientos autóctonos sobre el ambiente, y se las comienza a considerar como fuertemente "espirituales". Tal como señala un boletín del Proyecto Araucaria XXI:

La comunidad guaraní de la provincia de Misiones, al igual que la selva que los ampara, son resabios de un mundo que vivió en armonía, por comprender en su cosmovisión, una única integridad entre la vida y la muerte, entre la naturaleza y el espíritu, y por sobre toda las cosas, en el sentido de la pertenencia. La tierra no es de ellos, según su filosofía de vida, sino, que son ellos los que pertenecen a la tierra. El objetivo central de Proyecto Araucaria XXI, en particular el componente siete: contribuir a recuperar la identidad del mundo mbyá-guaraní (Curí 2009, p. 2).

Cabe destacar que el Proyecto Araucaria organiza reuniones "de recuperación de la espiritualidad guaraní”, donde se consensuó con los indígenas que para la asistencia a las mismas recibirían un pago en efectivo.

Otra nueva representación que se construye sobre indios y colonos está dada en considerarlos como "pobladores locales". Esta noción alude a quienes habitan las áreas sobre las que se despliega el nuevo paradigma. El término "local" se presenta como una referencia universal, ya que alude a lugares indiferenciados: cada rincón del planeta es un lugar local. La identidad que adquieren los "pobladores locales” se define por oposición a lo "global". A cada actor se le asigna un campo de acción. Las agencias transnacionales, nacionales, provinciales, los Estados, son actores "globales". A su vez, a cada tipo de actor se le asignan responsabilidades ligadas a su campo de acción: los globales planifican proyectos y políticas a implementar a diversos niveles, de ecorregión, ecosistema, nación, provincia, mientras los "locales" tienen las responsabilidades de ser los ejecutores en el campo de tales políticas y proyectos. Queda en evidencia la diferencia en capacidades de acción y poder entre unos y otros, lo cual trata de ser saldado por los que piensan a nivel "global" dándoles poder a los locales, o "empoderándolos" (término caro a este discurso ambientalista). Pero se trata de un poder restringido. La definición de "actores locales", por otro lado, se restringe a un determinado tipo de pobladores y productores. Entre las agencias de conservación y desarrollo tal concepto la idea de "locales" no refiere a las empresas forestales, ni siquiera a las empresas chicas, que no son cuestionadas en las lógicas que determinan su accionar sobre el ambiente, por representar una de las principales pilares de la economía regional, siendo aceptada su búsqueda de maximización de intereses.

\section{La visibilidad del territorio y la creación del Núcleo Norte}

La gobernabilidad del territorio que se gesta a partir de la presencia de las alianzas de agencias de conservación y desarrollo, implica resignificar el espacio, crear una nueva visibilidad del mismo. En términos generales, cuando a lo largo del siglo XX, el objetivo de las políticas de desarrollo era la ocupación agrícola del espacio misionero, se consideró a la selva como un freno al progreso, una barrera verde cuya expansión era necesario combatir para convertirla en agrícola. Pero con la nueva mirada conservacionista, la provincia de Misiones comienza a valorarse por ser uno de los últimos espacios con selva. El territorio misionero se presenta 
como parte del ambiente global, y como un componente fundamental, pasa a ser un "pulmón del planeta”. La selva aparece como un ambiente global a ser gestionado, cuidado, porque de él depende el bienestar del mundo. De manera que los "pobladores locales" adquieren una responsabilidad extra de ser "guardianes de la selva”.

En el caso de los Proyectos Araucaria XXI y Cabure í, focalizan su accionar en la zona norte de Misiones, región conformada por los departamentos Iguazú y General Manuel Belgrano. Esta región pasa a ser denominada como "Núcleo Norte" una región que necesita de urgente conservación. Si bien ambos Proyectos trabajan sobre los dos departamentos estos presentan importantes distinciones. Iguazú - más poblada que General Manuel Belgrano - posee una inclusión transnacional más fuerte como destino turístico y como área problemática. Ambos departamentos cuentan en su interior áreas naturales protegidas, aunque solo en los últimos años comienzan a ampliarse hasta incluir a General Manuel Belgrano los trabajos de planificación conjunta del manejo de Áreas Naturales Protegidas. En Iguazú, el turismo es por lejos la principal actividad económica, mientras que la hotelería y el comercio son las principales actividades productivas generadoras de trabajo. En General Manuel Belgrano, si bien comienzan a construirse alternativas económicas ligadas al turismo, la mayor parte de su población vive de actividades relacionadas con la producción primaria de las colonias. En la actualidad, los datos provisionales para el ańo 2010 señalan una población de 81.215 personas para el departamento Iguazú, y 42.929 para el departamento General Manuel Belgrano. La estructura demográfica es diferencial no solo en la cantidad de pobladores, sino en el tipo de pobladores, así, General Manuel Belgrano posee una población rural mejor representada estadísticamente que Iguazú ${ }^{2}$.
A su vez, el departamento General Manuel Belgrano es señalado como uno de los que cuenta con más altos índices de pobreza del país. No obstante, la diferencia significativa que interesa destacar entre estos dos departamentos es la densidad de agencias involucradas en la organización del desarrollo. El entramado de agencias estatales y descentralizadas, nacionales e internacionales es mucho más denso en Iguazú. Las ONGs intervinientes en problemas específicos, vinculadas por ejemplo a aldeas aborígenes, a pobladores ocupantes de tierras, a la creación y fortalecimiento de destinos turísticos, etc., son más, y más influyentes en Iguazú. La sistematización de datos inherentes a la distribución de agencias estatales y descentralizadas, nacionales e internacionales es inexistente con lo cual esta afirmación se basa sobre estudios etnográficos. La conformación por parte de pobladores locales, de ONGs, cooperativas, organismos estatales, agencias de desarrollo, comisiones cooperadoras, grupos de interés diversos, es lo que de manera poco disimulada se ofrece a la observación directa en las calles, comercios, y locales de Iguazú.

\section{Gobernabilidad como búsqueda de alianzas. Conservación con población}

Una de las bases de acción del Proyecto Araucaria XXI así como del Proyecto Cabure í, radica en lograr el involucramiento de las poblaciones locales, y que éstas participen de éstas. En buena medida esto se presenta como una de las columnas vertebrales que legitiman cada una de las acciones que las agencias llevan a cabo en la región. Pero también posibilita el accionar de las agencias, creando redes que incluyen a pobladores locales y abren la puerta a la formula conservación más desarrollo. La participación es institucionalizada y por medio de la misma las poblaciones locales, forman 
parte del aparato de gubernamentalización del territorio y la naturaleza. A continuación veremos cómo se presenta el vínculo entre agencias de de conservación y desarrollo y poblaciones locales, luego preponemos algunas líneas de trabajo para dar cuenta de que la respuesta de las poblaciones no es pasiva, no se acepta en bloque las bondades que se presentan en los discursos del desarrollo. Frente a los proyectos, estas poblaciones también generan enfrentamientos, negociaciones y alianzas.

Hacia mediados de la década de 1990 se inicia una serie de transformaciones en la relación entre pobladores rurales y el sector ambientalista. En un proceso que se fortalece con la presencia de los Proyectos Araucaria XXI y Cabure í, las estrategias de conservación dejan de tener por objetivo principal incrementar la cantidad de áreas protegidas, y apuntan a establecer puentes entre conservación y producción agrícola. Entre ambos sectores se crean alianzas que de a poco irán desdibujando los límites entre uno y otro, como consecuencia de lo cual se observa una expansión del ambientalismo a nivel de las colonias, así como el crecimiento de su legitimidad entre los colonos.

Las estrategias que desarrolla el sector conservacionista son fundamentalmente de dos tipos. Por un lado se gestó una nueva forma de expansión territorial, buscando conectar las reservas existentes, con lo cual se pretende consolidar corredores biológicos que abarcan grandes áreas e integran diversas de situaciones sociales, productivas y ambientales; el principal ejemplo de esto es el Corredor Verde Misionero. Otra de las estrategias radica en la expansión del ambientalismo hacia nuevos sectores sociales, fundamentalmente incorporándose en las actividades de conservación a agencias de desarrollo y a poblaciones locales. Las transformaciones que caracterizan este período pueden sintetizarse en cuatro procesos:
A) el sector ambientalista misionero se hace eco de cambios teóricos mundiales sobre estrategia de manejo de Áreas Naturales Protegidas, que apuntan a integrar a las poblaciones locales en los programas de conservación;

B) cuando en la provincia se agotan las tierras fiscales sin ocupantes, y no hay más tierras fiscales con selva a conservar, se comienza a trabajar en la conexión de las reservas existentes y la conservación al interior de unidades productivas de colonos;

C) las agencias de desarrollo rural comienzan a integrar perspectivas conservacionistas en sus programas;

D) el marcado empobrecimiento de los colonos durante la década de 1990 favoreció que muchos productores se sumasen a propuestas de producción sustentable o agroecológica.

Con respecto al primero de estos procesos, en los últimos años, a nivel global se incrementa la importancia dada a las poblaciones locales en el manejo de las Áreas Naturales Protegidas. Esto comienza a verse en las reuniones ambientalistas desde la década de 1990 y se profundiza entrado el siglo $\mathrm{XXI}^{3}$. Las ANP van siendo consideradas como territorios que deben resguardar el patrimonio natural y cultural intangible, ya no deben dedicarse sólo a la conservación de la biodiversidad. Inclusive uno de los objetivos de las ANP pasa a ser "asegurar la provisión de servicios ambientales y contribuir al desarrollo económico sostenible. Mientras en el ámbito local, deben mejorar la calidad de vida y contribuir a la superación de la pobreza" (CLPNy AP, 2007, p. 2) $)^{4}$.

De manera que no sólo se comienza a trabajar con la población que habita dentro o entorno a las ANP, sino que pasa a considerarse a estas poblaciones como parte de la "riqueza cultural” de las reservas. A su vez, y tal vez más importante, las ANP comienzan a presentarse como potenciales "ejes de ordenamiento regional sostenible". El documento previo al Con- 
greso Latinoamericano de Parques Nacionales y AP de Bariloche (2007) inclusive propone que "las ANP pueden convertirse en espacios claves que detonen el desarrollo regional y que favorezcan la superación de la pobreza y las desigualdades sociales" (CLPNy AP, 2007, p. 5). Claramente apunta a que estas Áreas Protegidas no constituyan un costo para los habitantes locales, sino por el contrario, que sean un beneficio que les permita mejorar su calidad de vida y tender hacia el desarrollo sostenible. Debemos aclarar que estos cambios de perspectiva, en Misiones se hacen notar de forma muy gradual, y lo expuesto en este punto apunta a señalar una tendencia general en las discusiones dadas en ámbitos internacionales.

En relación al segundo proceso señalado, en las nuevas estrategias implementadas por las agencias conservacionistas, también interviene el hecho de que durante la década de 1990 finaliza la expansión de la frontera agraria en la provincia, con lo cual termina la carrera entre el frente agrario y el frente conservacionista por ocupar los últimos espacios fiscales con selva. Ya no quedan más porciones públicas de selva por conservar, con lo cual los pasos que toma el frente conservacionista son consolidar las reservas ya existentes, lo que se plantea en la estrategia de establecer corredores biológicos y trabajar en la conservación de las selvas que se encuentran dentro de las unidades productivas, en tal sentido se proponen, por ejemplo, programas de desarrollo sustentable y proyectos de utilización de los bosques con fines no maderables, es decir sin desmontarlos.

Con respecto al tercer proceso, la configuración del sector ambientalista a partir de los ańos 1990 se caracteriza por contar con una fuerte participación de agencias de desarrollo rural que difunden perspectivas de desarrollo sustentable. Estas agencias permiten que el ambientalismo ingrese a la vida cotidiana de las colonias. De manera que en términos ge- nerales, estas agencias a la vez que denuncian y cuestionan el deterioro del medio ambiente derivado del modelo productivo basado en monocultivos, también impugnan las formas de distribución de la riqueza social, los procesos de concentración de la tierra y la pobreza. Las principales líneas de trabajo, además de aspectos productivos, persiguen el fortalecimiento organizativo de los productores, lo que incluye cuestionamientos de las relaciones de producción al interior del grupo doméstico. En términos generales, puede decirse que estas agencias buscan consolidar una agricultura familiar ecológica, niveles de comercialización local y la organización de los productores con participación de la mujer.

\section{Gobernanza medioambiental infraestructuras organizativas}

Las diferentes interdependencias sociales, entre personas, grupos, y organizaciones constituyen condiciones esenciales de las "infraestructuras organizativas" (Mc Adam et al, 1999). Son ellas las que, en sus palabras, “[...] permiten comprender mejor los patrones históricos de movilización y predecir en qué lugares existe una mayor posibilidad de que se generen movimientos sociales" (Mc Adam, Op. cit., p. 26). De manera análoga a los movimientos sociales el involucramiento con proyectos de desarrollo sustentable y con agencias ambientalistas emerge siempre sobre infraestructuras organizativas específicas. Sin duda, el entramado de agencias en el departamento de Iguazú es bastante más denso. Aunque no es allí donde se aplican proyectos de desarrollo sustentable fortaleciendo la gobernabilidad ambiental con tanta afluencia y participación de pobladores locales como en el departamento General Manuel Belgrano. Como reflexiona Arach (2003, p. 146), 
I 36 | Raimundo Elías Gómez \& Brian German Ferrero

Pareciera que a mayor "poder local" menor "vinculación global”. Más específicamente, que un mayor peso de las organizaciones, intereses, $y$ perspectivas "locales" restringe las posibilidades de articulación en un frente común hacia el nivel global [...].

Es decir, la similitud entre los movimientos sociales y el desarrollo sustentable es la necesaria e inevitable vinculación global que ambos comparten. La menor diferenciación de intereses y alternativas de representación política inciden en el involucramiento de los pobladores locales con proyectos de agencias ambientalistas transnacionales. Otros organismos estatales también poseen líneas de acción estrechamente relacionadas con poblaciones aledañas a áreas naturales protegidas, no obstante, la aceptación menos conflictiva por parte de los pobladores locales de los proyectos sustentables y de conservación debe algo a las peculiaridades del sistema ideacional del cual son parte aquellos. De Barros (1996, p. 123) ilustra de manera acertada esta particularidad:

El ambientalismo se presenta como portador de valores e intereses que se sobreponen a las diferencias de sexo, etnia, religión, clase o nacionalidad. Luego, se distingue de otros movimientos sociales por el hecho de sobreponerse a la necesidad de alineamiento a identidades específicas.

Acerca de las “infraestructuras organizativas” de Iguazú y General Manuel Belgrano, la amplitud de las divergencias y convergencias entre proyectos generan mayores posibilidades de experiencias y proyecciones diferentes en la población. Según Elias (1990, p. 215),

Cuanto mayor es, en el transcurso del desarrollo de la sociedad, el margen de diversificación de las experiencias que pueden grabarse en la memoria del individuo, mayores son las posibilidades de individualización.
De tal manera, habrá más intereses y problemáticas diferenciadas a medida que la complejidad de los entramados de relaciones entre agencias diversas, aumente. En este sentido es discutible la afirmación de Mc Adam (1999, p. 31):

A falta de la información y la perspectiva que aportan los demás, los individuos aislados tienen una marcada tendencia a explicar sus problemas recurriendo a defectos individuales más que del sistema. Solo cuando se atribuyen deficiencias al sistema se genera una base para la acción colectiva.

Si bien el autor refiere a la acción colectiva en general, los proyectos colectivos al menos en el caso del desarrollo sustentable, se benefician mayormente de condiciones sociales en las que no circulan con tanta fuerza ni la información, ni las perspectivas de otros grupos o pobladores. El que las personas reconozcan efectos sociales como originados en el sistema o en ellos mismos, depende de la complejidad de las interdependencias sociales. A mayor complejidad mayor individuación, es decir, mayor diferenciación de intereses y perspectivas, y más posibilidades de atribuir deficiencias y posibilidades al individuo. En consecuencia, menos probabilidades de parte de agencias transnacionales y descentralizadas de recrear, gestionar y administrar creencias y objetivos colectivos. Tales los objetivos de la "gobernanza medioambiental" como

sinónimo de las intervenciones destinadas a introducir cambios en el medio ambiente relacionados con los incentivos, los conocimientos, instituciones, la toma de decisiones y comportamientos (Lemos y Agrawal 2006, p. 298 traducción mía).

La participación de los productores rurales del núcleo norte en proyectos de agencias 
ambientalistas, como señala Ferrero (2005) está fuertemente asociado a los beneficios que puede traer participar en una "arena ambientalista” transnacional. Aun así, agencias estatales como INTA (Instituto Nacional de Tecnología Agropecuaria), PSA (Programa Social Agropecuario), organizaciones de productores rurales como UTR (Unión de trabajadores rurales) y UC (Unión campesina) operan con proyectos económico-productivos paralelos al accionar ambientalista, aunque con menor vinculación y poder transnacional. De modo que si bien son las agencias ambientalistas las que poseen una mayor apertura y reconocimiento de poblaciones contiguas y en no pocas ocasiones han intervenido sobre problemas de ocupación ilegal de tierras o expropiación de recursos de tierras aborígenes (Lenton, 2010), no son las únicas reconocidas y actuantes en la zona. No existe una oposición sistemática entre el accionar de agencias ambientalistas transnacionales o descentralizadas y el accionar de organismos estatales, de este modo "Una estructura politica regional o internacional no desplaza a la estructura de oportunidades nacionales sino que interactúa con ella" (Sikkink, 2003, p. 309, traducción mía). El rasgo característico de la nueva institucionalidad política de la gobernanza medioambiental es la consideración de que los actores locales deben participar en los procesos de gestión territorial, y que la conservación de los recursos naturales en áreas naturales protegidas no es posible si no va acompañada por el desarrollo y mejoramiento de la calidad de vida de las poblaciones que viven dentro o en torno a éstas. Es así como las agencias ambientalistas, incorporan de manera renovada el problema de la conservación de la naturaleza, al dominio civil y político del estado. A la vez, que en contacto con poblaciones locales reformulan los ejes del desarrollo sustentable.

\section{Consideraciones finales}

Debido a las infraestructuras organizativas y condiciones sociales diferenciales en el núcleo norte de la provincia de Misiones, la ejecución de proyectos ambientalistas implican en mayor medida y con mayor éxito a poblaciones asentadas en el departamento General Manuel Belgrano. Los estilos de acción de cooperación española y japonesa si bien no excluyentes ni opuestos entre si son diferentes, incorporando agentes y problemáticas disimiles en sus objetivos y proyectos.

Para Ribeiro (1991), diferentes sectores ambientalistas alientan al desarrollo sustentable proponiendo definiciones que son fundamentalmente ideologías. Desde este enfoque las ideologías nada tienen de despectivo, y más bien "[...] apuntan a una articulación selectiva con fines interpretativos, sean manipulativos o no" (Ribeiro, Op. Cit., p. 65), constituyendo juntos a otras ideologías, "sistemas ideacionales" (Ibid.). Al interior de la cosmografía ambientalista-colona (Ferrero, 2005; 2008) encontramos distintos tipos de configuraciones ambientalistas, según predominen acciones coordinadas por determinadas agencias ambientalistas, e interdependencias con diferentes estados mediante cooperación internacional. Las agencias ambientalistas desarrollan ideologías diferentes aunque similares en cuanto se enmarcan en la esfera más amplia de los sistemas ideacionales (Ribeiro, 1991) del ambientalismo. A partir de los estilos de acción de las agencias descriptas anteriormente, las posiciones ocupadas por las poblaciones contiguas a áreas naturales protegidas (así se trate de aborígenes o productores rurales), dependen de modo fundamental de la importancia de sus problemas e intereses para los objetivos planteados por agencias transnacionales y descentralizadas, e inherentes a la conservación y el desarrollo sustentable. Por un lado, encontramos un estilo de producción de 
información y manejo de tecnologías anclado en la capacitación y entrenamiento de personal de agencias y organismos involucrados con el manejo de áreas naturales protegidas. Y de otra parte, un estilo de intervención política y social tendiente a mejorar el bienestar general de las poblaciones aledañas a áreas naturales protegidas, tales los objetivos de la cooperación española para Argentina en la última década. En el primer caso las poblaciones objetivo de los proyectos son más bien beneficiarias y ejecutoras de planificaciones, y en el segundo caso aquellas son constructoras y poseedoras de problemáticas y características que interesan ser anexadas a la gestión ambiental.

En este caso, las interdependencias transnacionales de los diferentes estilos de cooperación para Argentina se orientan a regular o influir sobre diferentes áreas de acción del ambientalismo. El accionar de JICA se ejerce mayormente sobre ONGs y organismos estatales, involucrados en proyectos orientados a la conservación y el desarrollo sustentable. Mientras que el Accionar de AECID, persigue el involucramiento de poblaciones y factores históricamente relegados de la gestión y planificación de áreas naturales protegidas. De una forma $\mathrm{u}$ otra, la institucionalización de problemáticas ambientales avanza con éxito impulsada incluso por las mismas poblaciones locales, y las propuestas ambientalistas van siendo ampliadas, redefinidas y negociadas.

Algunas estrategias de intervención y problemas tratados de modo recurrente se encuentran en ambos estilos de conservación y desarrollo sustentable, mientras que otras cuestiones atañen de manera específica a uno u otro. El ambientalismo utiliza de manera frecuente en las justificaciones de sus proyectos concepciones esencialistas estratégicas (Brosius, 1999). No obstante, en la investigación social es importante, como afirma Nygren (1999, p. 270, traducción mía) “[...] analizar los conocimientos locales como formas de conocimiento sumamente situadas, que han estado sujetas a múltiples formas de dominación e hibridación”. Un caso ilustrativo de las interdependencias de conocimientos (y desconocimientos) situados, son las dificultades que encuentran las agencias ambientalistas para la ejecución de proyectos que implican la participación de poblaciones aborígenes. El olvido de las actividades a realizar, la falta de convencimiento acerca de los fines últimos a los que aportarían los proyectos, o la revitalización de prohibiciones y valoraciones ancestrales, etc., son estrategias típicas a las que recurren las poblaciones aborígenes estando ellas mismas habilitadas por las agencias ambientalistas a recurrir con legitimidad (y con bastante frecuencia lo hacen), a esas estrategias. Por otra parte la participación de los productores rurales junto a agencias transnacionales en acciones ambientalistas, lleva a los primeros a discutir y criticar las funciones y métodos de guardaparques y técnicos. De tal forma, los nuevos actores en escena disputan su papel a los tradicionales personajes relacionados con el cuidado del monte, esto es, a los guardaparques y técnicos de áreas naturales protegidas. Parte de estas disputas, se deben a que ambos pretenden roles similares, a veces como "guardianes" de la naturaleza y otras como "amigos" del monte. De allí que los productores rurales amplíen e intenten hacer reconocer sus saberes y tácticas relacionados con el monte, los animales y las plantas. Y para ello se sirven de las obligadas interacciones conjuntas que suponen la puesta en marcha de proyectos ambientalistas, en su mayor parte relacionados con AECID.

El desarrollo sustentable en el norte de Misiones es definida alguna veces como "auto desarrollo" (Curí 2009; 2010) en tanto tendencia que promueve el desarrollo latente en el interior de otras culturas, y otras veces como proceso que equilibra conservación y desarrollo 
(OPDR, 2008; 2009). En ambos casos la desigualdad de las poblaciones locales con frecuencia remite a la subordinación de unas culturas con valores y creencias dignas de ser sostenidas o revitalizadas (Aguyjevete, 2007). Estas concepciones esencialistas son para las agencias ambientalistas inevitables, en especial a la hora de tomar posiciones en defensa de poblaciones aborígenes, como recuerda Brosius (1999, p. 280, traducción mía),

Sea lo que sea lo que se propongan, los movimientos u organizaciones ambientalistas están preocupadas esforzándose por valorizar comunidades naturales o culturales que históricamente han estado disgregadas, subyugadas, o de otra forma, desprestigiadas.

El peligro que portan estas ideologías, especialmente cuando involucran a poblaciones aborígenes, es alertado por Cardoso de Oliveira (2007, p. 17)

Como resultado de este enfoque, las acciones se centran en la difusión del valor de las culturas de los discriminados, como si la desigualdad fuera un producto del desconocimiento mutuo, y no del sistema social interétnico.

No obstante la revalorización de culturas locales corresponde a una estrategia preliminar (y urgente) en la conformación de proyectos sustentables, que intenta dotar de existencia política a grupos en general subordinados o negados por organismos y políticas estatales. Es así como los objetivos del desarrollo sustentable deben gran parte de su razón de ser a que de manera obligada deben presentarse como yendo de suyo. Al menos en las conflictivas y endebles condiciones sociales de poblaciones contiguas a Áreas Naturales Protegidas del norte de Misiones, y acerca de los amenazados ecosistemas altoparanaenses. Con lo cual la pregunta principal, confusa, y problemática es a menudo soslayada “¿qué tipo de desarrollo queremos?, ¿queremos algún tipo de desarrollo?” (Ribeiro, 1991, p.239). Dejando de lado estas primeras interrogaciones vacilantes, las siguientes interdependencias sociales hacen oscilar proyectos de poblaciones locales aledañas y agencias ambientalistas, en un continuo proceso de negociaciones, aperturas y rebeliones sutiles.

La sustentabilidad de manera frecuente es definida en relación a "[...] la manutención de la capacidad de carga de los ecosistemas, es decir, a la capacidad de la naturaleza para absorber y recomponerse de las agresiones antrópicas" (Guimarães, 2002, p. 75). Diferenciar con claridad entre los objetivos del desarrollo y los objetivos de la sustentabilidad de ecosistemas, es imposible, aunque no por cuestiones lógicas y analíticas. Sino debido al marcado interés humano en alcanzar los segundos con la intención explícita de la adecuada y exitosa reproducción social de la propia especie. Interés que emerge incluso en las definiciones corrientes de sustentabilidad. A propósito del primer y segundo término de la pareja conceptual "desarrollo sustentable", puede ser que la máxima de Mefistófeles del "Fausto" de Goethe alerte sobre argucias no tanto infernales sino un poco humanas "Es ley para diablos y espectros, que por donde se colaron, por allí han de salir. Lo primero es libre para nosotros; de lo segundo somos esclavos" (Goethe, 2002, p. 85).

\section{Kinds of sustainable development in the North of Misiones}

abstract This paper provides an approach to the field of conservation and sustainable development in the north of Misiones. The central axis is the ways in which environmental agencies face projections and conservation interventions in buffer zones of protected naturals areas. At first outlined a description of the departments of General 
Manuel Belgrano and Iguazú and the beginnings of the formation of environmental governance. It then describes the main projects for the conservation and sustainable development stimulated by JICA (Japan International Cooperation Agency), and AECID (Spanish Agency for International Development). Concretely, the main characteristics of "Cabure í Project (JICA) and the projects produced by Araucaria XXI (AECID). Towards the end, we present considerations on recurrent problems that bring together local communities and environmental agencies.

keywords Gobernability. Sustainable Development. Cosmographies. Environmentalism.

\section{Notas}

1. Área de amortiguamiento o "buffer zone" es la denominación de la franja de territorio que rodea al núcleo de las áreas naturales protegidas. La función de esta zona sería, de forma concreta, la de amortiguar el efecto antrópico sobre los ecosistemas resguardados.

2. Según censo nacional 2001.

3. Por ejemplo puede verse en el IV Congreso IV Congreso Mundial de Parques Nacionales realizado en Caracas, (1992), el I Congreso Latinoamericano de Parques Nacionales y Otras Áreas Protegidas, en Santa Marta (Colombia, 1997), o el V Congreso Mundial de Parques en Durban (Sudáfrica, 2003).

4. En el documento preparatorio al II Congreso Latinoamericano de Parques Nacionales y otras Áreas Protegidas (Bariloche, 2007) se señala que "Las ANP no solo son los espacios que permiten la evolución de la biodiversidad del planeta y su conservación en el largo plazo, sino que son también los espacios más importantes que proporcionan un conjunto de servicios ambientales que no han sido valorados y que ofrecen a la población humana opciones económicas directas para el bienestar social" (Comité Organizador CLPNy AP, 2007, p.4).

\section{Referências bibliográficas}

AGUYJEVETE. Los hijos de la selva. Documento del componente "Autodesarrollo del pueblo Mbya Guarani". Araucaria XXI, Misiones, 2007.
ARACH, Omar. "Ambientalismo, desarrollo y transnacionalidad: las protestas sociales en torno a las represas de Yaciretá". In: Elizabeth Jelín (Comp.). Más allá de la nación: las escalas múltiples de los movimientos sociales. Buenos Aires: Libros del Zorzal, 2003.

BROSIUS, Peter. Analyses and Interventions. Anthropological Engagements with Environmentalism. Current Anthropology, Chicago, v. 40, n. 3, 1999. p. 277-310.

CARDOSO DE OLIVEIRA, Roberto. Etnicidad y estructura social. Clásicos y Contemporáneos en Antropología. México: CIESAS, 2007.

CLPN y AP. Actas de Congreso Internacional, II Congreso Latinoamericano de Parques Nacionales y Otras Áreas Protegidas. Bariloche, 2007.

CURÍ. Boletín electrónico del proyecto regional araucaria XXI bosque atlántico. Araucaria XXI. Misiones, Diciembre, 2009.

Boletín electrónico del proyecto regional araucaria XXI bosque atlántico. Araucaria XXI. Misiones, Diciembre, 2010.

DE BARROS, Flávia Lessa. Ambientalismo, globalização e novos atores sociais. Sociedade e estado. Rio de Janeiro, v.11, n.1. Jun., 1996.

ELIAS, Norbert. La sociedad de los individuos. Ediciones Península: Barcelona, 1990.

FERRERO, Brián. La selva en Disputa. Superposición de cosmografias agraria y ambientalista en la provincia de Misiones. Tesis (doctorado en Antropología Social). Facultad de Humanidades y Ciencias Sociales, Universidad Nacional de Misiones, Misiones, 2007.

Estudio de la gestión territorial y de los recursos naturales, de la población rural del Área de Influencia de la Reserva de Biosfera Yabotí-Argentina-. Buscando alternativas para un desarrollo local sustentable en torno a una Reserva de Biosfera. Programa Man and Biosphera. Unesco, 2005.

FOUCAULT, Michel. "Espacios de poder". Traducción de Julia Varela y Fernando Alvarez-Uría. In: CASTEL, Robert et al. Genealogía del poder, V. 6. Madrid: Editorial La Piqueta, 1991. p. 9-26.

GIRAUDO, A. H.; POVEDANO, M.; BELGRANO, E.; KRAUCZUK, U.; PARDIÑAS, A.; MIQUELARENAS, D.; LIGIER, D.; BALDO, M.; CASTELINO. "Biodiversity status of the Interior Atlantic Forest of Argentina". In: GALINDO-LEAL; CAMARA (eds.) The Atlantic Forest of South America: Biodiversity status, Threats and Outloock. Washington D. C.: Island Press, 2003.

GUIMARÃES, Roberto. "La ética de la sustentabilidad y la formulación de políticas de desarrollo". In: ALI- 
MONDA, Héctor (comp.) Ecología Politica. Naturale$z a$, sociedad y utopia. CEPAL: Santiago de Chile, 2002.

GOEHTE, Johan Wolfgang. Fausto. San Juan: Editorial de la Universidad de Puerto Rico, [1952] 2002.

JAPAN WILDLIFE RESEARCH CENTRE. Proyecto de Conservación del Ambiente Natural en la Región de Iguazú de la República Argentina. Informe de Relevamiento de Información Básica. Proyecto Cabure í. Misiones, 2005.

LEMOS, María; AGRAWAL, Arun. Environmental Governance. Annual Review of Environment and Natural Resources. California: v. 31, 2006. p. 297-325.

LENTON, Diana. Informe sobre daño cultural en la comunidad Iriapú. Araucaria XXI. Misiones, 2010.

RIBEIRO, Gustavo Lins. Ambientalismo y desarrollo sustentable. Nueva ideología/utopía del desarrollo. Revista de Antropologia, São Paulo, n.34, 1991. p.59-101.

MC ADAM, Dough; MC CARTHY, Johny; ZALD, Mayer (Eds.) Movimientos sociales: perspectivas comparadas. París: Istmo, 1999.

MINISTERIO DE PRODUCCIÓN SECRETARÍA DE TURISMO ADMINISTRACIÓN DE PARQUES. Informe de Actividades desarrolladas y en desarrollo en el Municipio de Comandante Andresito (Sector Este de la Zona de Amortiguación del PN Iguazú), 2009.
NYGREN, Anja. Local Knowledge in the Environment-Development Discourse: From dichotomies to situated knowledges. Critique of Anthropology. California, v. 19, n. 3 1999. p. 267-288.

OPDR (OFICINA DE PROYECTOS DE DESARROLLO REGIONAL). Raid náutico Andresito - Cataratas 2008 Informe de actividades. Parque Nacional Iguazú. APN. 2008.

OPDR (OFICINA DE PROYECTOS DE DESARROLLO REGIONAL). Raid náutico Andresito - Cataratas 2008 Informe de actividades. Parque Nacional Iguazú. APN. 2007.

PROYECTO CABURE Í. Censo de uso de la tierra en el área de estudio del Proyecto Cabure-i. Informe Proyecto de conservación del ambiente natural en la región de Iguazú de la República Argentina. Diciembre, 2005.

PROYECTO CABURE Í. Informe de avance. Actividades efectuadas entre marzo y diciembre de 2004. Informe Proyecto de Conservación del Ambiente Natural en la Región de Iguazú, de la República Argentina, 2004.

SIKKINK, Kathrin. "La dimensión transnacional de los movimientos sociales". In: Jelín Elizabeth (comp.). Más allá de la nación, las escalas múltiples de los movimientos sociales. Buenos Aires: Libros del Zorzal, 2003.

\section{autor Raimundo Elías Gómez}

Estudiante de Maestría en Antropología Social/ PPAS-UNaM

autor Brian German Ferrero

Investigador Adjunto / CONICET-Argentina

Recebido em 21/03/2011

Aceito para publicação em 26/09/2011 